\title{
Applying Hybrid PSO to Optimize Directional Overcurrent Relay Coordination in Variable Network Topologies
}

\author{
Ming-Ta Yang ${ }^{1}$ and An Liu ${ }^{2,3}$ \\ ${ }^{1}$ Department of Electrical Engineering, St. John's University, 499, Section 4, Tam King Road, Tamsui District, New Taipei 25135, Taiwan \\ ${ }^{2}$ Department of Computer Science and Information Engineering, St. John's University, 499, Section 4, Tam King Road, Tamsui District, \\ New Taipei 25135, Taiwan \\ ${ }^{3}$ Graduate Institute of Computer and Communication Engineering, National Taipei University of Technology, No. 1, Section 3, \\ Chunghsiao E. Road, Taipei 10608, Taiwan
}

Correspondence should be addressed to Ming-Ta Yang; mtyang@mail.sju.edu.tw

Received 4 December 2012; Revised 20 January 2013; Accepted 25 January 2013

Academic Editor: Frank Werner

Copyright (C) 2013 M.-T. Yang and A. Liu. This is an open access article distributed under the Creative Commons Attribution License, which permits unrestricted use, distribution, and reproduction in any medium, provided the original work is properly cited.

In power systems, determining the values of time dial setting (TDS) and the plug setting (PS) for directional overcurrent relays (DOCRs) is an extremely constrained optimization problem that has been previously described and solved as a nonlinear programming problem. Optimization coordination problems of near-end faults and far-end faults occurring simultaneously in circuits with various topologies, including fixed and variable network topologies, are considered in this study. The aim of this study was to apply the Nelder-Mead (NM) simplex search method and particle swarm optimization (PSO) to solve this optimization problem. The proposed NM-PSO method has the advantage of NM algorithm, with a quicker movement toward optimal solution, as well as the advantage of PSO algorithm in the ability to obtain globally optimal solution. Neither a conventional PSO nor the proposed NM-PSO method is capable of dealing with constrained optimization problems. Therefore, we use the gradient-based repair method embedded in a conventional PSO and the proposed NM-PSO. This study used an IEEE 8-bus test system as a case study to compare the convergence performance of the proposed NM-PSO method and a conventional PSO approach. The results demonstrate that a robust and optimal solution can be obtained efficiently by implementing the proposal.

\section{Introduction}

The aim of relay coordination in power systems is to quickly isolate fault areas to preserve service throughout most of the power systems. Protection relays play a primary role in the coordination of power system protection, covering five basic facets: reliability, selectivity, speed of operation, simplicity, and economic feasibility. Engineers must consider these five aspects as a group to overcome the problem of power system protection. During the past 40 years, the technology used in the creation and use of relays for power system protection has seen tremendous progress. Directional overcurrent relays (DOCRs) have been applied to the design of economical alternatives for the primary or backup protection of power systems. Most work on protection coordination is geared toward determining the values of time dial setting (TDS) and plug setting (PS) of the DOCRs [1].

Many studies on optimization have addressed the coordination of DOCRs. Since Urdaneta et al. [2] first introduced a methodology based on optimization principles, these techniques have been widely investigated to deal with the problem of optimal coordination of DOCRs in interconnected power networks. Urdaneta et al. [2] applied an iterative approach, the Gauss-Seidel method, to solve steadystate fixed configurations DOCRs optimization problems, and decomposition technique and hierarchical coordination procedure were adopted to find DOCRs optimal settings under steady-state multiple configurations. This study applies linear programming technique to determine the DOCRs optimal settings. TDS are calculated given the PS; then new 
PS are computed after the TDS are found, and this process is repeated until convergence is achieved. Birla et al. [3] adopted the sequential quadratic programming method to simultaneously optimize all TDS and PS for each DOCR of the system. The constraints based on the near-end faults for small systems were considered, when the objective function optimal values were calculated. However, constraints based on both the nearend and the far-end faults of large interconnection systems were taken into account. Noghabi et al. [4] introduced the concept of robust coordination for the DOCRs coordination problem and considered simultaneously a large number of coordination constraints corresponding to a set of network topologies, and an efficient genetic algorithm (GA) method combined with linear programming (LP) is proposed to solve the optimization problem. Noghabi et al. [5] applied the interval analysis technique to drastically reduce the number of coordination constraints when solving the DOCRs coordination problem of a large interconnection system. Abyaneh et al. [6] adopted the theory of optimization technique [7] and considered the relays whose characteristics are linearly and nonlinearly proportional to TDS when solving the DOCRs optimal setting problem. Bedekar and Bhide [8] treated the DOCRs coordination optimal problem as a nonlinear programming problem. They first applied GA to find an initial guess of the solution and then used nonlinear programming technique to determine the globally optimal solution.

Particle swarm optimization (PSO) theory was introduced by Eberhart and Kennedy in 1995 as a means to handle nonlinear optimization problems [9], which has now been expanded to include a wide range of applications related to optimization. Del Valle et al. [10] presented an extensive discussion on the basic concepts, variants, and applications of PSO in power systems. The PSO technique can be applied to power system problems such as reactive power and voltage control, economic dispatch, power system reliability and security, generation expansion problem, state estimation, load flow and optimal power flow, short-term load forecasting, and capacitor placement. Wu [11] proposed a hybrid real-coded genetic algorithm with a PSO algorithm and a hybrid artificial immune algorithm with a PSO algorithm to solve global optimization problems with 13 constraints. Kao et al. [12] proposed a new hybrid algorithm based on two main swarm intelligence approaches, the ant colony optimization (ACO) and the PSO to solve capacitated vehiclerouting combinatorial optimization problems. Zhang et al. [13] proposed an improved PSO algorithm to solve a bilevel multiobjective programming problem (BLMPP) in the upper level and the lower level interactively and repeatedly until the accurate Pareto optimal solutions of the original problem were found.

There are other literatures that applied the modified PSO approach for the DOCRs optimal coordination problem. Mansour et al. [14] proposed a repair algorithm which enabled the PSO algorithm to solve a constrained optimization coordination problem that has been solved as an LP problem. Zeineldin et al. [15] proposed a modified PSO algorithm which treated the DOCRs coordination problem as a mixed integer nonlinear programming problem and determined both the optimal discrete PS and continuous
TDS. This proposal is far more superior to the original PSO algorithm and the general algebraic modeling system solvers in finding a near-optimal solution for the coordination problem.

This study is an attempt to supplement the findings of these earlier studies. It is similar to the previous studies discussed above, in that the focus is on the protection coordination of DOCRs using the PSO algorithm. However, this study differs from the previous works in its approach to assess nonlinear programming for the TDS and PS for DOCRs. Little research has been done on the simultaneous consideration of the TDS and PS for the coordination optimization of DOCRs. In addition to near-end faults, this study incorporates far-end faults into the objective function and takes into account a large number of coordination constraints in the optimal coordination problem. Due to the changeability of system topology, various network topologies were included in this study. As a result, the DOCRs coordination problem is a complex optimization problem with many nonlinear constraints, and a hybrid PSO method is applied to determine the optimal relay settings. This study shows that the proposed hybrid PSO method not only is efficient but also improves the convergence of conventional PSO.

\section{Formulation of the DOCRs Coordination Issue}

The principal aim of the coordination problem of DOCRs is to determine the TDS and PS of each relay. Then the optimal operating times of the primary relays can be minimized, for the protection coordination pairs of primary/backup relays coordination constraints to be satisfied. Therefore, the optimization objective function can be described as follows:

$$
\operatorname{minObj}=\sum_{i=1}^{N_{\text {near }}} t_{\text {near }}^{i}+\sum_{j=1}^{N_{\text {far }}} t_{\text {far }_{\text {primary }}}^{j},
$$

where $N_{\text {near }}$ and $N_{\text {far }}$ are the number of primary relays responding to near-end and far-end faults, respectively. The

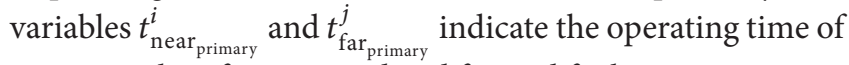
primary relays for near-end and far-end faults.

2.1. Coordination Criteria. The coordination constraints between the primary and the backup relays are as follows:

$$
\begin{gathered}
t_{\text {near }_{\text {backup }}}^{i}-t_{\text {near }}^{i} \text { primary }_{\text {f }} \\
t_{\text {far }_{\text {backup }}}^{j}-t_{\text {far }_{\text {primary }}}^{j} \geq \mathrm{CTI},
\end{gathered}
$$

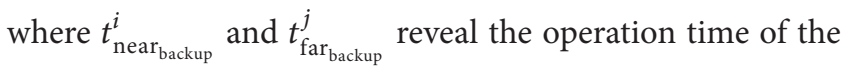
backup relay for the near-end and far-end faults, respectively. CTI is the minimum coordination time interval between backup and primary relay; the aim of the time interval is to ensure that circuit breakers clear the fault as directed. There are several factors influencing the operating time of relays, including CT error, the dc offset component of fault current, and relay overtravel. Therefore, typical CTI ranges from 0.2 to $0.5 \mathrm{~s}$. In this study, a CTI of $0.2 \mathrm{~s}$ was selected. 
2.2. Relay Characteristics. The nonlinear relay characteristics function based on standard IEEE C37.112-1996 can be stated as follows:

$$
t^{i}=\operatorname{TDS}^{i} \times\left(\frac{28.2}{\left(I_{\text {s.c }}^{i} / I_{p}^{i}\right)^{2}-1}+0.1217\right)
$$

The constants 28.2, 0.1217, and 2 in (3) define the shape of the extremely inverse trip characteristics.

2.3. Bounds on the TDS and PS of Relays. The time dial setting TDS $^{i}$ is the adjustable delay of the $i$ th relay. In this study, the $\mathrm{TDS}^{i}$ values range from 0.1000 to 1.1000 :

$$
0.1000 \leq \operatorname{TDS}^{i} \leq 1.1000 .
$$

$I_{p}^{i}$ is the pickup current setting of the $i$ th relay. As usual the value of $I_{p}^{i}$ can be determined by

$$
\begin{aligned}
& \text { 2(maximum value of load current) } \\
& \qquad \leq I_{p}^{i} \leq \frac{1}{2} \text { (minimum value of fault current). }
\end{aligned}
$$

In (5), the "2" of 2 times maximum value of load current represents safety factor, and the " 2 " of $1 / 2$ times minimum value of fault current represents dependability. In this study, the $I_{p}^{i}$ values range from 10 to 1000 , for each relay. The PS is equal to $I_{p}^{i}$ divided by the CT ratio. The current transformer (CT) ratio for each relay is $500: 1$.

Consider,

$$
\begin{gathered}
\frac{I_{p}^{i}}{\mathrm{CT} \text { ratio }}=\mathrm{PS}, \\
0.02 \leq \mathrm{PS} \leq 2 .
\end{gathered}
$$

$I_{s . c}^{i}$ is the short circuit current passing through the $i$ th relay.

2.4. Variable Network Topology Constraints. When line(s) outage occur(s), loading change or equipment is maintained; modifying network topology can improve power quality, ensuring that power supply is not affected or the duration of power failure is shortened. Once the network topology changes, the original TDS and PS values of DOCRs' settings in the system are no longer suitable for the protection coordination under the new network topology. Among the literature, only $[4,5]$ deal with the impact of changes in the network topology on protection coordination. Adopting the original parameter settings at this point leads to miscoordination of DOCRs. Therefore, it is necessary to investigate new sets of coordination constraints corresponding to various network topologies.

In consideration of changes in network topology, (2) are revised as

$$
\begin{aligned}
& \left(t_{\text {near }}^{i}{ }_{\text {backup }}\right)^{s}-\left(t_{\text {near }}^{i}{ }_{\text {primary }}\right)^{s} \geq \mathrm{CTI}, \quad s \in S, \\
& \left(t_{\text {far }_{\text {backup }}}^{j}\right)^{s}-\left(t_{\text {far }_{\text {primary }}^{j}}\right)^{s} \geq \mathrm{CTI}, \quad s \in S,
\end{aligned}
$$

where $S$ is the set of all topologies, when a single line outage occurs in the main topology.

\section{Hybrid Nelder-Mead Method and Particle Swarm Optimization}

The advantage of the PSO method [9] is that it belongs to the class of global search procedures; however, numerous particles are required, and the convergence can be very slow. To compensate for problems such as these, this study adopts PSO as the basic structure and uses the Nelder-Mead (NM) simplex search method [16] to form a hybrid Nelder-Mead simplex search method and particle swarm optimization. This method avoids falling easily into the local best solution with the added feature of the NM search method, which increases the rate of movement in the correct direction. This hybrid optimization method can lead to relatively rapid convergence to find a feasible and optimal solution. The following case study makes it is even clearer that the proposed NM-PSO method is superior to conventional PSO methods. This is an important contribution of this study. A conventional PSO method is incapable of dealing with constrained optimization problems. Therefore, the proposed NM-PSO method must be combined with a gradient-based repair method $[17,18]$ to overcome NLP problems with constraints.

Next, we introduce the algorithm procedure of the proposed NM-PSO. Assuming that the question to be solved is in $n$ dimensions, we first produce $N$ particles $(N>$ $n+1$, according to the experimental results of the case study) to form a swarm. For every particle that violates the constraints, we use the gradient repair method to direct infeasible solutions toward feasible regions, and in most cases, the repair method is successful in doing this. Next we arrange the calculation results of the objective function in the order of good to bad and divide the $N$ particles into three groups, that is, $n$ particles, the $(n+1)$ th particle, and $N-(n+1)$ particles. We calculate the top $n$ particles and the $(n+1)$ th particle using the NM simplex method. The $(n+1)$ th particle is quickly modified to move in the correct direction, which is the key to the proposed algorithm. Through the calculation of a simple NM algorithm, the probability of finding the preferable optimal solution is increased. Subsequently, we employ the PSO method to adjust all of the $N$ particles, which (of course) include the best particles using the NM simplex method. This procedure for adjusting the $N$ particles involves the selection of the global best particle, selection of the neighborhood best particle, and finally the velocity updates. Thus, the global best particle of the population is determined. The entire NM-PSO optimal process is repeated until the termination condition is fulfilled. The details of the theory of the proposed NM-PSO algorithm are shown in $[18,19]$.

\section{Simulation Results}

An IEEE 8-bus test system was used to test and demonstrate the proposed method for solving a new problem formulated for the optimal protection coordination of relays. The 8-bus 
TABLE 1: Primary/backup relay pairs and the fault currents in a fixed network topology.

\begin{tabular}{|c|c|c|c|c|c|}
\hline \multicolumn{2}{|c|}{$\mathrm{P} / \mathrm{B}$ relay pairs } & \multicolumn{2}{|c|}{ Near-end fault current (A) } & \multicolumn{2}{|c|}{ Far-end fault current (A) } \\
\hline Primary relay no. & Backup relay no. & Primary relay & Backup relay & Primary relay & Backup relay \\
\hline 1 & 6 & 3230 & 3230 & 995 & 995 \\
\hline 8 & 9 & 6080 & 1160 & 2990 & 553 \\
\hline 8 & 7 & 6080 & 1880 & 2990 & $78^{*}$ \\
\hline 2 & 1 & 5910 & 993 & 3550 & 393 \\
\hline 9 & 10 & 2480 & 2480 & 1160 & 1160 \\
\hline 2 & 7 & 5910 & 1880 & 3550 & 746 \\
\hline 3 & 2 & 3550 & 3550 & 2240 & 2240 \\
\hline 10 & 11 & 3880 & 2340 & 2480 & 1140 \\
\hline 6 & 5 & 6100 & 1200 & 3230 & 626 \\
\hline 6 & 14 & 6100 & 1870 & 3230 & $78^{\#}$ \\
\hline 13 & 8 & 2980 & 2980 & 986 & 986 \\
\hline 14 & 9 & 5190 & 1160 & 1870 & $151^{\#}$ \\
\hline 7 & 5 & 5210 & 1200 & 1890 & $181^{\#}$ \\
\hline 14 & 1 & 5190 & 993 & 1870 & $986^{*}$ \\
\hline 7 & 13 & 5210 & 985 & 1890 & $994^{*}$ \\
\hline 4 & 3 & 3780 & 2240 & 2400 & 1050 \\
\hline 11 & 12 & 3700 & 3700 & 2340 & 2340 \\
\hline 5 & 4 & 2400 & 2400 & 1200 & 1200 \\
\hline 12 & 13 & 5890 & 985 & 3700 & 433 \\
\hline 12 & 14 & 5890 & 1870 & 3700 & 821 \\
\hline
\end{tabular}

* Passing through DOCRs fault current flow reverse direction.

" Passing through DOCRs fault current fall below their pickup current.

system comprises 7 lines, 2 transformers, and 14 DOCRs, as shown in Figure 1. The system parameters are stated in [4]. At bus 4 , there is a link to another network modeled by a short circuit capacity of $400 \mathrm{MVA}$. However, the network topology is usually assumed to be fixed. In practice, the system may be operated in different topologies due to transmission lines outage. In order to take all the various network topologies into account, a large number of coordination constraints must be met. This study considers a variable network topology under steady-state rather than under transient-state as discussed in [20]. Additional constraints, such as the miscoordination caused by large transient currents in the backup relays of protection relay pairs resulting from the tripping of nearby relays, are not considered in this study.

It is assumed that all of the DOCRs have IEEE standard inverse-time characteristics as mentioned above in (3). When the values of TDS and PS of DOCRs need to be solved simultaneously, the relay coordination problem can be formulated as a nonlinear programming problem. 20 particles are used to solve an $n$-dimensional problem in this study. Therefore, the population size in the NM-PSO method is $20 \times n+1$, and the population size in the PSO method is $20 \times n$, where $n=28$ is the number of the PS and TDS for the 14 DOCRs.

A Matlab 7 program is developed to implement the NMPSO algorithm and a conventional PSO algorithm and is executed on a PC with an Intel Core i5 3.1 GHz CPU and 4 GB RAM.
TABLE 2: Results of a conventional PSO and the proposed NM-PSO in a fixed network topology.

\begin{tabular}{lcccc}
\hline \multirow{2}{*}{ Relay no. } & \multicolumn{2}{c}{ PSO } & \multicolumn{2}{c}{ NM-PSO } \\
& PS & TDS & PS & TDS \\
\hline 1 & 0.4644 & 0.2171 & 0.4911 & 0.1854 \\
2 & 1.0728 & 0.5065 & 1.1621 & 0.4096 \\
3 & 0.5681 & 0.6440 & 0.7506 & 0.3810 \\
4 & 0.4553 & 0.7807 & 0.6156 & 0.5056 \\
5 & 0.4861 & 0.2293 & 0.6632 & 0.1491 \\
6 & 1.1828 & 0.2348 & 0.4056 & 1.0842 \\
7 & 0.5468 & 0.5244 & 0.7574 & 0.2783 \\
8 & 0.5518 & 0.7422 & 0.7954 & 0.3902 \\
9 & 0.6187 & 0.1462 & 0.4075 & 0.2891 \\
10 & 0.3648 & 1.0287 & 1.0075 & 0.2176 \\
11 & 0.4392 & 1.0460 & 0.7999 & 0.3419 \\
12 & 0.7757 & 0.9921 & 1.1674 & 0.4226 \\
13 & 0.4754 & 0.2358 & 0.6585 & 0.1000 \\
14 & 0.5058 & 0.6784 & 0.594 & 0.4299 \\
\hline Obj-Fun & \multicolumn{3}{c}{6.1328} & \multicolumn{2}{c}{5.5514} \\
\hline
\end{tabular}

4.1. Fixed Network Topology. In this study, the minimization of the objective function and coordination constraints are based on the consideration of simultaneous near-end fault 
TABLE 3: Operation times of primary/backup relay pairs in a fixed network topology (with near-end faults and far-end faults) using the proposed NM-PSO method.

\begin{tabular}{|c|c|c|c|c|c|c|c|c|c|}
\hline \multicolumn{5}{|c|}{ Near-end fault } & \multicolumn{5}{|c|}{ Far-end fault } \\
\hline \multicolumn{2}{|c|}{ Backup relay } & \multicolumn{2}{|c|}{ Primary relay } & \multirow{2}{*}{$\begin{array}{l}\text { Constraint } \\
\text { value (sec) }\end{array}$} & \multicolumn{2}{|c|}{ Backup relay } & \multicolumn{2}{|c|}{ Primary relay } & \multirow{2}{*}{$\begin{array}{l}\text { Constrain } \\
\text { value (sec) }\end{array}$} \\
\hline No. & $\begin{array}{l}\text { Operating } \\
\text { time (sec) }\end{array}$ & No. & $\begin{array}{l}\text { Operating } \\
\text { time (sec) }\end{array}$ & & No. & $\begin{array}{l}\text { Operating } \\
\text { time (sec) }\end{array}$ & No. & $\begin{array}{l}\text { Operating } \\
\text { time (sec) }\end{array}$ & \\
\hline 6 & 0.2583 & 1 & 0.0583 & 0.2000 & 6 & 3.6456 & 1 & 0.3792 & 3.2664 \\
\hline 9 & 0.3337 & 8 & 0.1335 & 0.2002 & 9 & 1.8970 & 8 & 0.2701 & 1.6270 \\
\hline 7 & 0.3799 & 8 & 0.1335 & 0.2464 & $x$ & $x$ & $x$ & $x$ & $x$ \\
\hline 1 & 0.3800 & 2 & 0.1799 & 0.2001 & 1 & 3.3115 & 2 & 0.3954 & 2.9161 \\
\hline 10 & 0.2830 & 9 & 0.0830 & 0.2000 & 10 & 0.8607 & 9 & 0.3337 & 0.5270 \\
\hline 7 & 0.3799 & 2 & 0.1799 & 0.2000 & 7 & 2.3585 & 2 & 0.3954 & 1.9631 \\
\hline 2 & 0.3954 & 3 & 0.1954 & 0.2000 & 2 & 0.9306 & 3 & 0.3752 & 0.5554 \\
\hline 11 & 0.3895 & 10 & 0.1895 & 0.2000 & 11 & 1.2643 & 10 & 0.2830 & 0.9813 \\
\hline 5 & 0.3046 & 6 & 0.0914 & 0.2132 & 5 & 1.1760 & 6 & 0.2583 & 0.9177 \\
\hline 14 & 0.4390 & 6 & 0.0914 & 0.3476 & $x$ & $x$ & $x$ & $x$ & $x$ \\
\hline 8 & 0.2713 & 13 & 0.0713 & 0.2000 & 8 & 1.8682 & 13 & 0.4391 & 1.4291 \\
\hline 9 & 0.3337 & 14 & 0.1281 & 0.2056 & $x$ & $x$ & $x$ & $x$ & $\times$ \\
\hline 5 & 0.3046 & 7 & 0.1045 & 0.2001 & $x$ & $\times$ & $x$ & $x$ & $x$ \\
\hline 1 & 0.3807 & 14 & 0.1281 & 0.2526 & $x$ & $x$ & $x$ & $x$ & $x$ \\
\hline 13 & 0.4391 & 7 & 0.1045 & 0.3346 & $x$ & $x$ & $x$ & $x$ & $x$ \\
\hline 3 & 0.3752 & 4 & 0.1752 & 0.2000 & 3 & 1.5123 & 4 & 0.2949 & 1.2174 \\
\hline 12 & 0.4316 & 11 & 0.2316 & 0.2000 & 12 & 0.9111 & 11 & 0.3895 & 0.5217 \\
\hline 4 & 0.2949 & 5 & 0.0949 & 0.2000 & 4 & 0.9170 & 5 & 0.3046 & 0.6124 \\
\hline 13 & 0.4391 & 12 & 0.2389 & 0.2002 & 13 & 2.8975 & 12 & 0.4316 & 2.4659 \\
\hline 14 & 0.4390 & 12 & 0.2389 & 0.2000 & 14 & 2.0881 & 12 & 0.4316 & 1.6565 \\
\hline
\end{tabular}

$\mathrm{x}$ : both the primary protection and the backup protection are unavailable because the current flowing through the DOCRs is either too small or in the wrong direction.

TABLE 4: Primary/backup relay pairs and the fault currents after the removal of Line 65.

\begin{tabular}{|c|c|c|c|c|c|}
\hline \multicolumn{2}{|c|}{$\mathrm{P} / \mathrm{B}$ relay pairs } & \multicolumn{2}{|c|}{ Near-end fault current (A) } & \multicolumn{2}{|c|}{ Far-end fault current (A) } \\
\hline Primary relay no. & Backup relay no. & Primary relay & Backup relay & Primary relay & Backup relay \\
\hline 1 & 6 & 2990 & 2990 & 940 & 940 \\
\hline 8 & 9 & 6130 & 1320 & 3130 & 1080 \\
\hline 8 & 7 & 6130 & 1780 & 3130 & 433 \\
\hline 2 & 1 & 5760 & 939 & 4320 & 705 \\
\hline 9 & 10 & 1430 & 1430 & 1320 & 1320 \\
\hline 2 & 7 & 5760 & 1780 & 4320 & 1340 \\
\hline 3 & 2 & 4320 & 4320 & 3520 & 3520 \\
\hline 10 & 11 & 1540 & 0 & 1430 & 0 \\
\hline 6 & 14 & 5480 & 2440 & 2990 & 433 \\
\hline 13 & 8 & 3130 & 3130 & 1290 & 1290 \\
\hline 14 & 9 & 5290 & 1320 & 2450 & 1130 \\
\hline 14 & 1 & 5290 & 939 & 2450 & $1290^{*}$ \\
\hline 7 & 13 & 4320 & 1290 & 1780 & $939^{*}$ \\
\hline 4 & 3 & 5060 & 3520 & 4000 & 2790 \\
\hline
\end{tabular}

${ }^{*}$ Passing through DOCRs fault current flow reverse direction. 
TABLE 5: Operation times of primary/backup relay pairs after the removal of Line 65 (near-end faults).

\begin{tabular}{lcccc}
\hline \multicolumn{2}{c}{$\begin{array}{c}\text { Backup relay } \\
\text { Operating } \\
\text { No. }\end{array}$} & No. & $\begin{array}{c}\text { Primary relay } \\
\text { Operating } \\
\text { time }(\mathrm{sec})\end{array}$ & $\begin{array}{c}\text { Constraint } \\
\text { value }(\mathrm{sec})\end{array}$ \\
\hline 6 & 0.2982 & 1 & 0.0636 & 0.2346 \\
9 & 0.2576 & 8 & 0.1328 & 0.1248 \\
7 & 0.4212 & 8 & 0.1328 & 0.2884 \\
1 & 0.4254 & 2 & 0.1866 & 0.2388 \\
10 & 0.6050 & 9 & 0.2204 & 0.3847 \\
7 & 0.4212 & 2 & 0.1866 & 0.2346 \\
2 & 0.2853 & 3 & 0.1572 & 0.1281 \\
14 & 0.2903 & 6 & 0.1066 & 0.1837 \\
8 & 0.2542 & 13 & 0.0673 & 0.1869 \\
9 & 0.2576 & 14 & 0.1264 & 0.1312 \\
1 & 0.4254 & 14 & 0.1264 & 0.2990 \\
13 & 0.2625 & 7 & 0.1233 & 0.1392 \\
3 & 0.1974 & 4 & 0.1397 & 0.0577 \\
\hline
\end{tabular}

TABLE 6: Results of a conventional PSO and the proposed NM-PSO in variable network topologies.

\begin{tabular}{lcccc}
\hline \multirow{2}{*}{ Relay no. } & \multicolumn{2}{c}{ PSO } & \multicolumn{2}{c}{ NM-PSO } \\
& PS & TDS & PS & TDS \\
\hline 1 & 0.7999 & 0.4297 & 0.5527 & 0.8140 \\
2 & 0.8892 & 1.0540 & 1.1418 & 0.7155 \\
3 & 0.7498 & 0.7342 & 0.7524 & 0.7288 \\
4 & 1.1999 & 0.2423 & 1.1897 & 0.2440 \\
5 & 0.7921 & 0.2679 & 0.9099 & 0.2056 \\
6 & 0.6497 & 1.0998 & 0.7380 & 0.9772 \\
7 & 0.7674 & 0.6715 & 0.6342 & 0.8892 \\
8 & 0.8868 & 0.7033 & 0.7692 & 0.8726 \\
9 & 0.4900 & 0.6088 & 0.7801 & 0.2616 \\
10 & 1.0138 & 0.3585 & 0.9784 & 0.3580 \\
11 & 0.6267 & 1.0189 & 0.5887 & 1.0794 \\
12 & 1.1804 & 0.7422 & 1.0699 & 0.8652 \\
13 & 0.5661 & 0.8237 & 0.6198 & 0.7069 \\
14 & 0.7781 & 0.6595 & 0.6128 & 0.9878 \\
\hline Obj-Fun & 65.0723 & \multicolumn{2}{c}{64.6398} \\
\hline
\end{tabular}

and far-end fault occurrence. In this subsection, we consider the fixed network topology to solve the coordination optimization problem using a conventional PSO and the proposed NM-PSO.

Table 1 demonstrates the primary/backup relay pairs and corresponding near-end and far-end fault currents passing through them for the test system. There are 34 inequality constraints corresponding to each relay pair.

To find the optimal value of the object function, the program is run 10 times independently for each algorithm with 300 iterations in each run, and the best results of each run are recorded. Figure 2 shows the convergence characteristics in finding the best values. The proposed NM-PSO method converges to the optimal object function value in $5.5514 \mathrm{~s}$
TABLE 7: 10 independent runs of a conventional PSO and the proposed NM-PSO in variable network topologies.

\begin{tabular}{lcc}
\hline 10 independent runs & PSO & NM-PSO \\
\hline 1 & 65.0723 & 64.6398 \\
2 & 66.6168 & 65.6285 \\
3 & 65.2207 & 65.6045 \\
4 & 67.0376 & 65.6308 \\
5 & 66.0238 & 65.5951 \\
6 & 67.0316 & 64.7014 \\
7 & 66.9528 & 65.5822 \\
8 & 66.7907 & 64.8591 \\
9 & 66.7058 & 65.3773 \\
10 & 66.1551 & 65.0092 \\
\hline Mean & 66.3607 & 65.2628 \\
Standard deviations & 0.72601 & 0.41393 \\
\hline
\end{tabular}

in approximately 52 iterations, whereas a conventional PSO method converges to the optimal object function value in $6.1328 \mathrm{~s}$. Due to the added feature of the proposed NM search method which increases the rate of movement in the correct direction, a globally optimal solution is more likely reached than a locally optimal solution. The result of an example case of 20 particles shows that the output of the proposed NM-PSO method converges rapidly to a feasible and optimal solution.

The optimal values of the PS and TDS for both the proposed NM-PSO method and a conventional PSO method, considering fixed network topology are presented in Table 2. The operating times of primary/backup relay pairs for nearend and far-end faults are shown in Table 3. The constraint values are larger or equal to 0.2 in the column of Table 3 . This means that all the coordination constraints have satisfied the coordination criteria.

4.2. Variable Network Topologies. When modifications are required in the network topology due to changes in load demand or emergency conditions, continued use of the TDS and PS values of DOCRs as system settings planned according to fixed network topology will lead to miscoordination. For example, in Figure 2, when Line 65 was removed, the network topology changed in response. The new relationship of primary/backup relay pairs and new fault current at this point is shown in Table 4. Under this condition, Table 5 shows the operating time of primary/backup relay pairs and constraint values between them. In this table, there are some constraint values that do not satisfy the coordination criteria.

Using an IEEE 8-bus test system, consideration of single line outage leads to seven different network topologies. The near-end faults and far-end faults in these seven circumstances result in a total of 136 primary/backup relay pairs that must satisfy coordination constraints. To find the optimal values of the PS and TDS for both the proposed NM-PSO method and a conventional PSO method, the program is run 10 times independently for each algorithm with 300 iterations in each run, and the best result of each run is recorded in Table 6. Figure 3 shows the convergence characteristics in 


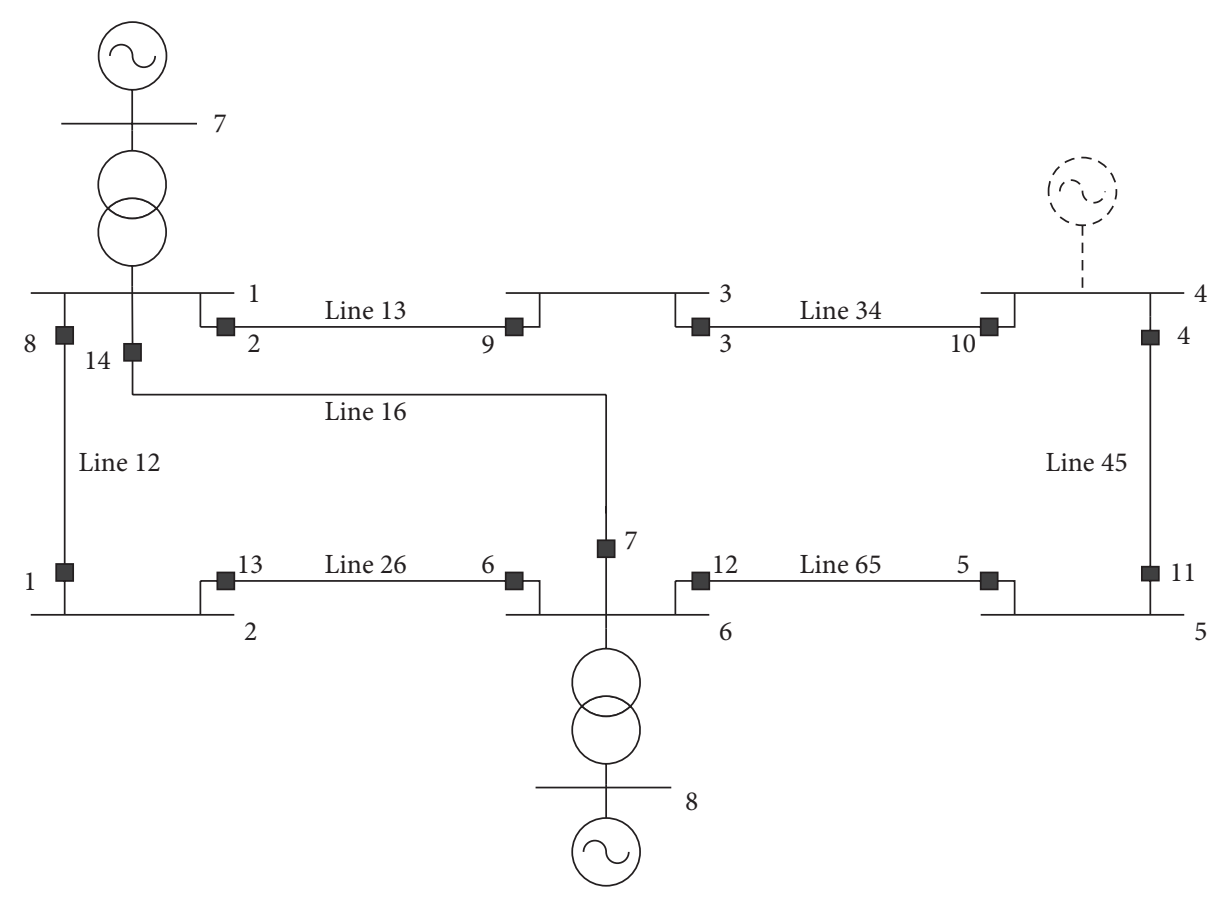

FIGURE 1: One-line diagram for an IEEE 8-bus test system.

TABLE 8: Operation times of primary/backup relay pairs after the removal of Line 65 (near-end faults) using the proposed NM-PSO method.

\begin{tabular}{lcccc}
\hline \multicolumn{2}{c}{$\begin{array}{c}\text { Backup relay } \\
\text { Operating } \\
\text { time }(\mathrm{sec})\end{array}$} & No. & $\begin{array}{c}\text { Primary relay } \\
\text { Operating } \\
\text { time }(\mathrm{sec})\end{array}$ & $\begin{array}{c}\text { Constraint } \\
\text { value }(\mathrm{sec})\end{array}$ \\
\hline 6 & 0.5452 & 1 & 0.2968 & 0.2484 \\
9 & 0.7377 & 8 & 0.2034 & 0.5343 \\
7 & 0.9302 & 8 & 0.2034 & 0.7267 \\
1 & 2.2755 & 2 & 0.2873 & 1.9883 \\
10 & 1.3815 & 9 & 0.6249 & 0.7566 \\
7 & 0.9302 & 2 & 0.2873 & 0.6429 \\
2 & 0.4457 & 3 & 0.2457 & 0.2000 \\
14 & 0.5666 & 6 & 0.2445 & 0.3221 \\
8 & 0.4834 & 13 & 0.2834 & 0.2000 \\
9 & 0.7377 & 14 & 0.2140 & 0.5237 \\
1 & 2.2755 & 14 & 0.2140 & 2.0616 \\
13 & 1.3070 & 7 & 0.2441 & 1.0630 \\
3 & 0.3261 & 4 & 0.1261 & 0.2000 \\
\hline
\end{tabular}

finding the best values. As stated previously, the proposed NM-PSO method converges to an optimal solution faster than a conventional PSO method because the proposed NM-PSO method has a higher rate of movement in the correct direction and converges to a globally optimal solution more likely than a locally optimal solution. Although faster convergence and better optimal values can be obtained by increasing the number of particles, the complexity of the optimization process will also increase. The statistical results

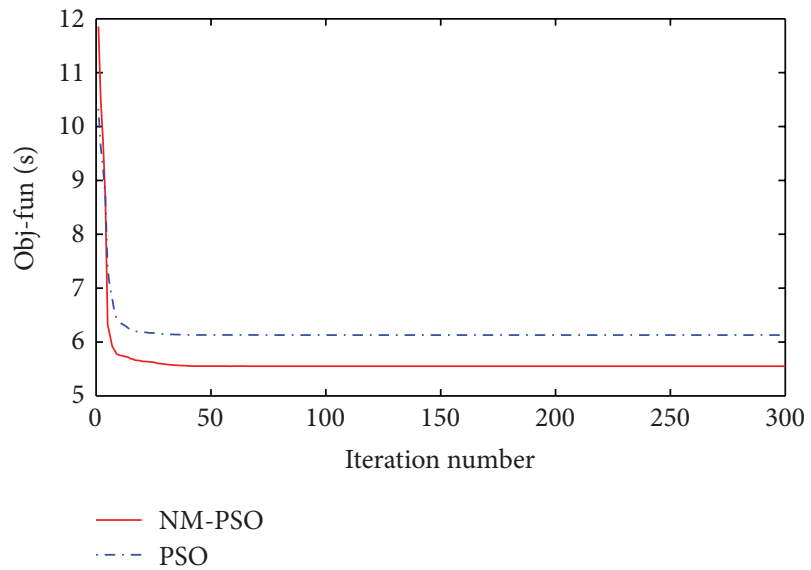

FIGURE 2: Convergence characteristics of a conventional PSO and the proposed NM-PSO in a fixed network topology.

for 10 independent runs are shown in Table 7. Together Tables 6 and 7 demonstrate the superiority of NM-PSO. The operating times of primary/backup relay pairs with constraint values between them are examined, and the results are listed in Table 8. The fact that the results conform to requirements demonstrates the robustness of the proposed NM$\mathrm{PSO}$ algorithm in dealing with large numbers of coordination constraints.

\section{Conclusions}

In this paper, the coordination optimization problem is represented by a nonlinear relay characteristic function and 


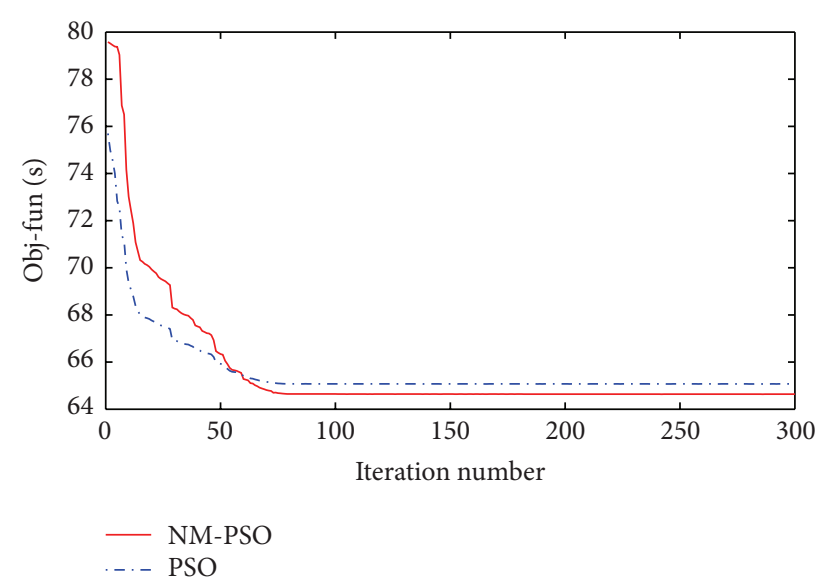

FIgURE 3: Convergence characteristics of a conventional PSO and the proposed NM-PSO in variable network topologies.

a range of nonlinear coordination constraints. A detailed formulation of the optimal DOCRs coordination problem in variable network topologies is presented. This study proposes an NM-PSO method to find an optimal solution for the complex optimization problem such that a large number of coordination constraints corresponding to various network topologies are satisfied simultaneously. The proposed method has the advantages of NM and PSO methods but none of their individual drawbacks and finds the optimal solution more accurately and efficiently. It has been shown that the proposed NM-PSO method outperforms a conventional PSO method.

\section{Abbreviations}
$N_{\text {near }}$ : The number of primary relays responding to near-end faults
$N_{\text {far }}$ : The number of primary relays responding to far-end faults
$t_{\text {near }}^{i}$ : The operating time of primary relays for near-end faults
$t_{\text {far }_{\text {primary }}} \quad$ : The operating time of primary relays for far-end faults
$t_{\text {near }}^{i}$ backup The operation time of the backup relay for the near-end faults
$t_{\text {far }_{\text {backup }}}^{j}$ : The operation time of the backup relay for the far-end faults
CTI: The coordination time interval
TDS $^{i}$ : The time dial setting of the $i$ th relay
$I_{p}^{i}$ : The pickup current setting of the $i$ th relay
PS: $\quad$ The plug setting
CT ratio: The current transformer ratio
$I_{s . c}^{i}$ : The short circuit current passing through the $i$ th relay.

\section{References}

[1] P. M. Anderson, Power System Protection, McGraw-Hill, New York, NY, USA, 1999.
[2] A. J. Urdaneta, R. Nadira, and L. G. Perez Jimenez, "Optimal coordination of directional overcurrent relays in interconnected power systems," IEEE Transactions on Power Delivery, vol. 3, pp. 903-911, 1988.

[3] D. Birla, R. P. Maheshwari, and H. O. Gupta, "A new nonlinear directional overcurrent relay coordination technique, and banes and boons of near-end faults based approach," IEEE Transactions on Power Delivery, vol. 21, no. 3, pp. 1176-1182, 2006.

[4] A. S. Noghabi, J. Sadeh, and H. R. Mashhadi, "Considering different network topologies in optimal overcurrent relay coordination using a hybrid GA," IEEE Transactions on Power Delivery, vol. 24, no. 4, pp. 1857-1863, 2009.

[5] A. S. Noghabi, H. R. Mashhadi, and J. Sadeh, "Optimal coordination of directional overcurrent relays considering different network topologies using interval linear programming," IEEE Transactions on Power Delivery, vol. 25, no. 3, pp. 1348-1354, 2010.

[6] H. A. Abyaneh, M. Al-Dabbagh, H. K. Karegar, S. H. H. Sadeghi, and R. A. J. Khan, "A new optimal approach for coordination of overcurrent relays in interconnected power systems," IEEE Transactions on Power Delivery, vol. 18, no. 2, pp. 430-435, 2003.

[7] S. S. Rao, Optimization: Theory and Applications, Halsted Press, New York, NY, USA, 1984.

[8] P. P. Bedekar and S. R. Bhide, "Optimum coordination of directional overcurrent relays using the hybrid GA-NLP approach," IEEE Transactions on Power Delivery, vol. 26, no. 1, pp. 109-119, 2011.

[9] R. Eberhart and J. Kennedy, "A new optimizer using particle swarm theory," in Proceedings of the 6th International Symposium on Micro Machine and Human Science, pp. 39-43, Nagoya, Japan, October 1995.

[10] Y. del Valle, G. K. Venayagamoorthy, S. Mohagheghi, J. C. Hernandez, and R. G. Harley, "Particle swarm optimization: basic concepts, variants and applications in power systems," IEEE Transactions on Evolutionary Computation, vol. 12, no. 2, pp. 171-195, 2008.

[11] J. Y. Wu, "Solving constrained global optimization problems by using hybrid evolutionary computing and artificial life approaches," Mathematical Problems in Engineering, vol. 2012, Article ID 841410, 36 pages, 2012.

[12] Y. Kao, M. H. Chen, and Y. T. Huang, "A Hybrid algorithm based on ACO and PSO for capacitated vehicle routing problems," Mathematical Problems in Engineering, vol. 2012, Article ID 726564, 17 pages, 2012.

[13] T. Zhang, T. Hu, Y. Zheng, and X. Guo, "An improved particle swarm optimization for solving bilevel multiobjective programming problem," Journal of Applied Mathematics, vol. 2012, Article ID 626717, 13 pages, 2012.

[14] M. M. Mansour, S. F. Mekhamer, and N. E. S. El-Kharbawe, "A modified particle swarm optimizer for the coordination of directional overcurrent relays," IEEE Transactions on Power Delivery, vol. 22, no. 3, pp. 1400-1410, 2007.

[15] H. H. Zeineldin, E. F. El-Saadany, and M. M. A. Salama, "Optimal coordination of overcurrent relays using a modified particle swarm optimization," Electric Power Systems Research, vol. 76, no. 11, pp. 988-995, 2006.

[16] J. A. Nelder and R. Mead, "A simplex method for function minimization," Computer Journal, vol. 7, pp. 308-313, 1965.

[17] P. Chootinan and A. Chen, "Constraint handling in genetic algorithms using a gradient-based repair method," Computers and Operations Research, vol. 33, no. 8, pp. 2263-2281, 2006. 
[18] A. Liu and M. T. Yang, "A new hybrid Nelder-Mead particle swarm optimization for coordination optimization of directional overcurrent relays," Mathematical Problems in Engineering, vol. 2012, Article ID 456047, 18 pages, 2012.

[19] A. Liu, E. Zahara, and M. -T. Yang, "A modified NM-PSO method for parameter estimation problems of models," Journal of Applied Mathematics, vol. 2012, Article ID 530139, 12 pages, 2012.

[20] A. J. Urdaneta, L. G. Pérez, and H. Restrepo, "Optimal coordination of directional overcurrent relays considering dynamic changes in the network topology," IEEE Transactions on Power Delivery, vol. 12, no. 4, pp. 1458-1464, 1997. 


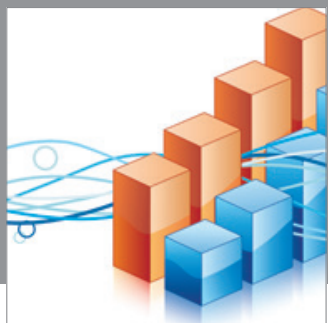

Advances in

Operations Research

mansans

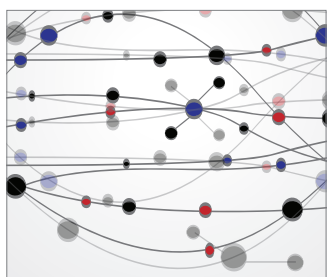

The Scientific World Journal
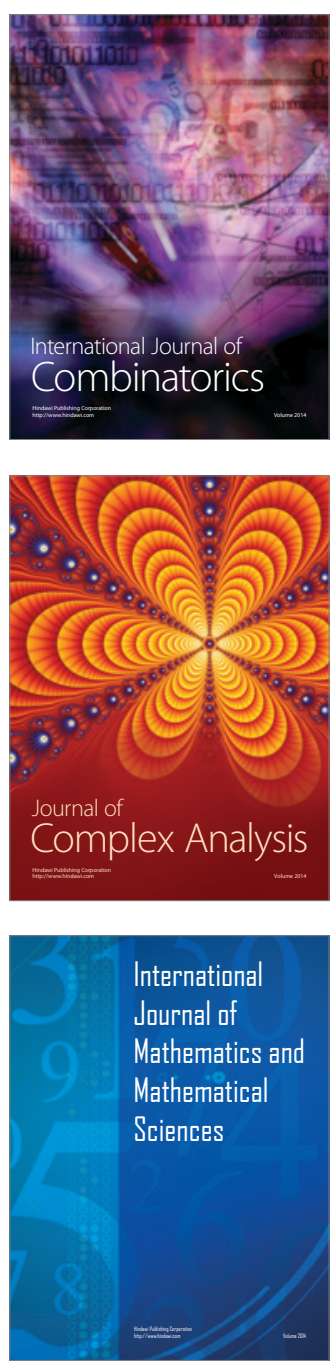
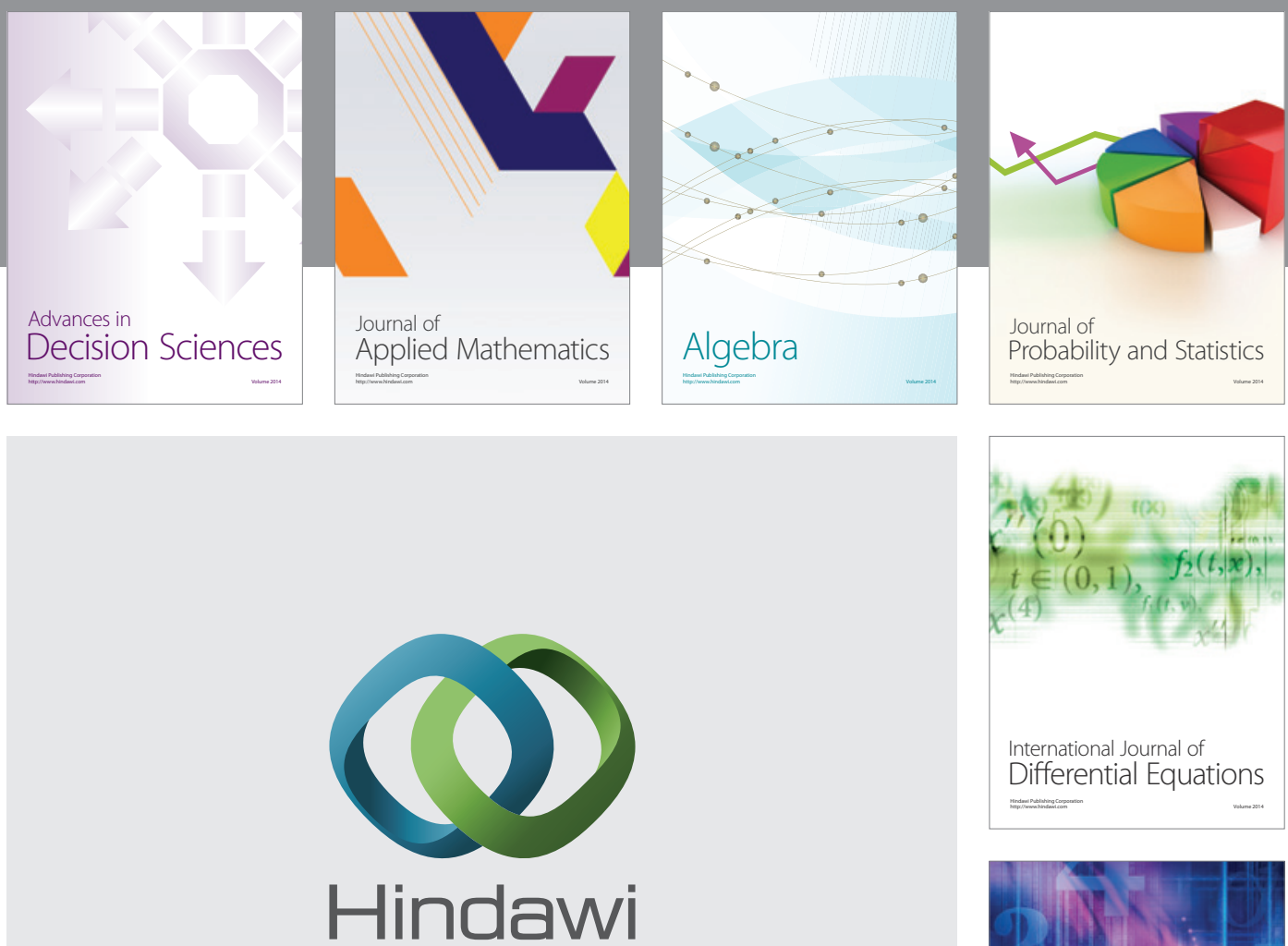

Submit your manuscripts at http://www.hindawi.com
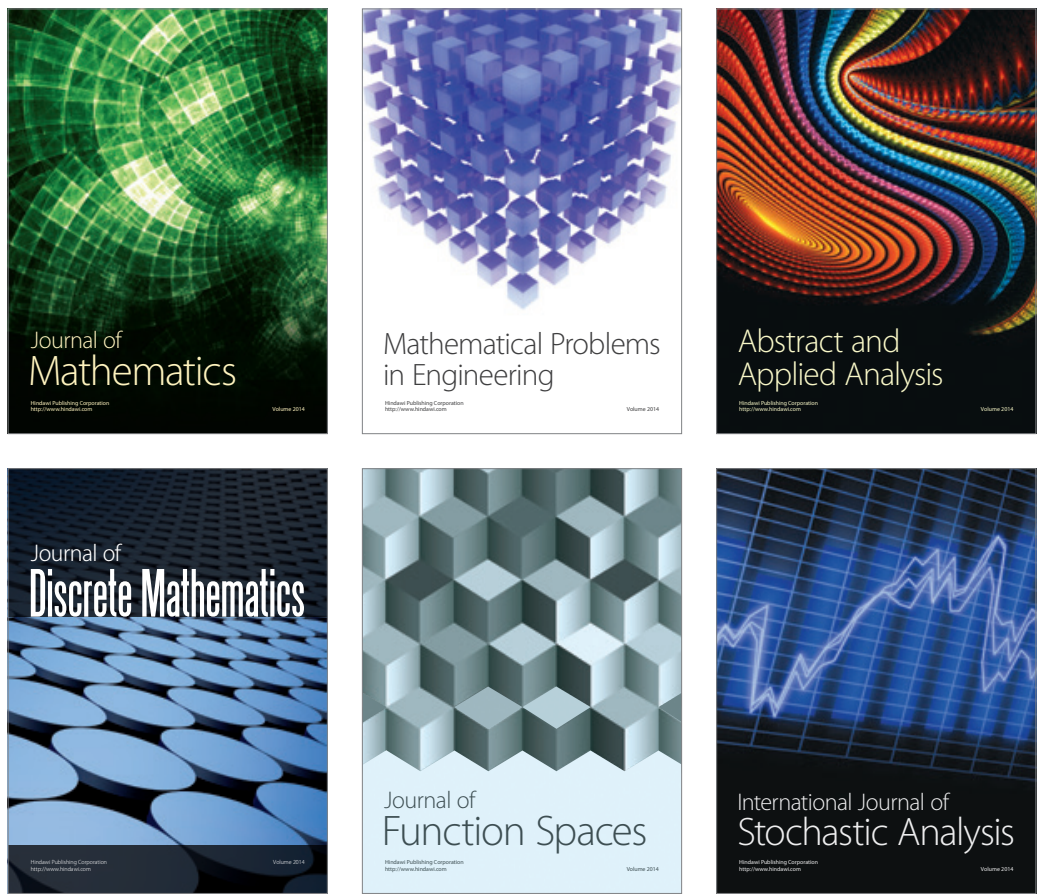

Journal of

Function Spaces

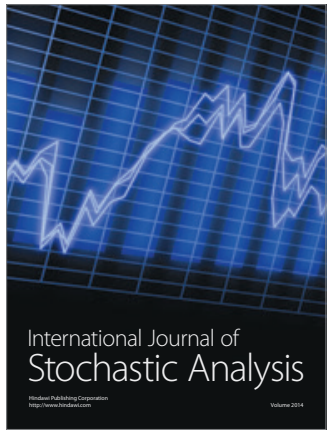

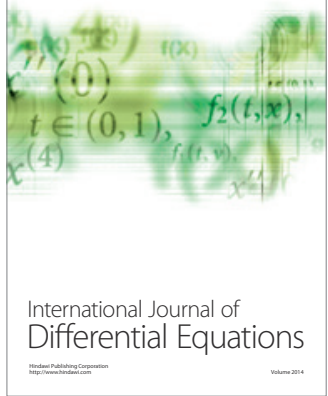
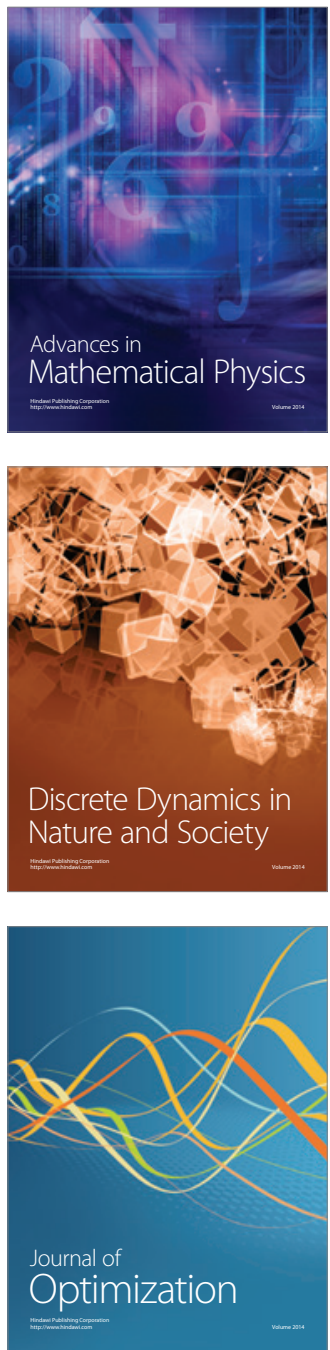